\title{
Practices and the Direct Perception of Normative States
}

\section{Part II}

Zahle, Julie

Published in:

Philosophy of the Social Sciences

DOI:

$10.1177 / 0048393112462517$

Publication date:

2014

Document version

Early version, also known as pre-print

Citation for published version (APA):

Zahle, J. (2014). Practices and the Direct Perception of Normative States: Part II. Philosophy of the Social Sciences, 44(1), 74-85. https://doi.org/10.1177/0048393112462517 


\section{Practices and the Direct Perception of Normative States: Part II}

Julie Zahle

Section of Philosophy, Department of Media, Cognition and Communication, University of Copenhagen

jzahle@hum.ku.dk

Final Draft - published in Philosophy of the Social Sciences, vol. 44(1)

The overall aim of this two-part paper is to provide a supplement to ability theories of practice in terms of a defense of the following thesis: Individuals' ability to act appropriately sometimes depends on their exercise of the ability directly to perceive normative states. In Part I, I presented the account of direct perception. In this Part II of the paper, I argue that, by the lights of this account, normative states are sometimes directly perceptible. Also, I show that the ability directly to perceive normative states is a commonly possessed - and exercised - ability. On this basis, I establish the conclusion that, in situations of social interaction, individuals' ability to act appropriately is sometimes underwritten by their exercise of the ability directly to perceive normative states. By way of ending, I briefly explain the different ways in which my discussion constitutes both a useful supplement to ability theories of practice and a reply to an important objection raised against these theories.

Keywords: practices, norms, perception, abilities, normative states

\section{The Ability Directly to Perceive Normative States}

In part I of this paper, I presented the account of direct perception. It is compatible with the assumption that everyday phenomena, such as tomatoes and their being ripe, are directly perceptible. By appeal to this account, I now take on the task of showing that normative states are sometimes directly perceptible too. More specifically, I arguethat if it is granted that everyday phenomena, such as tomatoes and their being ripe, are directly perceptible, then, in light of the account of direct perception, it follows that normative states are sometimes directly perceptible too. The development of the account of direct perception involved a discussion of perception first as state, then as process. I proceed in a parallel manner when examining whether normative states are sometimes directly perceptible.

\section{Perception as State: True Beliefs about Normative States}

According to the account of direct perception, perceptual states are true beliefs to the effect that the environment in front of one's eyes is a certain way. It must now be shown that individuals sometimes form true beliefs about normative states that fit this characterization. A single example will do to make this point. Consider an individual who is sitting in a crowded bus. She is looking in the direction of the bus door when an elderly person enters. It is uncontroversial to maintain that the individual may form the true belief that the situation makes it appropriate for her to offer her bus seat to the elderly person. In this manner, the example brings out that individuals may form true beliefs to the effect that the environment in front of their eyes makes some action appropriate or inappropriate.

\section{Perception as Process: Stimulation of the Retinal Cells}

Turning to perception as process, the account of direct perception has it that in perception the environment causes the stimulation of individuals' retinal cells via the light it emits and reflects. It is quite 
clear that individuals' true beliefs about normative states may be caused by the environment in this fashion.

To see this, notice that situations of social interaction may cause individuals to form true belief about the normative states of these situations. Or put differently, individuals respond to situations of social interaction by forming true beliefs to the effect that a given situation makes some action appropriate or inappropriate. Once this is realized, it is only a small step to see that environments may cause individuals' beliefs via the stimulation of their retinal cells: Individuals' use of their eyes alone may suffice for the generation of these beliefs. ${ }^{1}$ Return for a moment to the bus example. The individual is sitting with a view to the entrance in the crowded bus. When the bus stops, an elderly person enters. The situation here causes the individual to form the belief that she should offer the elderly person her seat. The individual only has to make use of her eyes to arrive at this belief. ${ }^{2}$ Generalizing from this example, it is reasonable to hold that situations of social interaction may, via the light they emit and reflect, cause the stimulation of individuals' retinal cells such that they form true beliefs to the effect that the situation in front of their eyes makes some action appropriate or inappropriate. Accordingly, true beliefs about normative states may be brought about in a way that accords with the first part of the specification of perception as process.

\section{Perception as Process: Noninferential Acquisition}

There is also the second part of the characterization of perception as process. It states that the stimulation of individuals' retinal cells initiates a process that does not involve any inferential activity among conceptual representations before it culminates in a perceptual belief. It must further be demonstrated that true beliefs about normative states may meet this condition. From what has been said so far, this is not obvious. The discussion has only shown that perception may play a role in the generation of true beliefs about normative states insofar as these beliefs may be caused by the environment via the stimulation of individuals' retinal cells. Yes this point is compatible with holding that these true beliefs about normative states are not perceptual because they are inferentially acquired. First I dwell at some length on this point and show how inferential activity may be involved in the formation of true beliefs about normative states. Then I move on to argue that true beliefs about normative states may be noninferentially acquired too.

In order to present the idea that inferential activity contributes to the formation of true beliefs about normative states, it is useful to clarify two issues: What kinds of properties of an environment make the performance of a given action appropriate or inappropriate? And what kinds of properties must individuals have in order for an environment to make it appropriate or inappropriate for them to act in a given manner?

To begin with the environment, there are various kinds of properties of an environment that, either on their own or in combination, partly make the performance of an action appropriate or inappropriate. These include the setting in which the acting individual finds herself, the objects present, the social status of the other individuals present, their physical/biological characteristics, and/or the actions or activities in which they are engaged:

\footnotetext{
${ }^{1}$ Henceforth, I shall talk interchangeably about the stimulation of individuals' retinal cells and individuals making use of their eyes.

${ }^{2}$ Needless to say, this should not be taken to imply that individuals in situations of this kind may not - and do not make use of their other senses. Moreover, the point is compatible with the observation that in many situations of social interaction, individuals' use of their eyes is insufficient or even dispensable when it comes to the formation of beliefs about normative states.
} 
- A setting is exemplified by a bus, a lecture hall, a school, a beach, Pittsburgh, the US, and a Western country. Settings may (partly) make an action appropriate or inappropriate: Being on the beach makes it appropriate for women to wear a bikini only, whereas being in a church makes the same attire highly inappropriate. ${ }^{3}$

- An object is exemplified by a table, a chair, an altar, a throne, and a fork. Objects may (partly) make an action appropriate or inappropriate: Something being a table makes it inappropriate to put one's feet on it, just as something being a fork makes it appropriate to put it in the mouth.

- A social status is exemplified by being a passenger, a guest, a queen, a policeman, a priest, a member of the local chess club, a pedestrian, and an American. Somebody else's social status may (partly) make it appropriate or inappropriate for an individual to act in a certain manner: Somebody being a queen makes it appropriate to address her with "your majesty."

- A physical/biological characteristic is exemplified by being old, young, a man, a woman, and fat. Somebody else's physical/biological characteristic may (partly) make it appropriate or inappropriate for an individual to act in a certain manner: A person being old makes it appropriate for an individual to offer the old person her bus seat if there are no available seats. ${ }^{4}$

- An action or activity is exemplified by reading, sleeping, stepping onto the bus, cleaning the table, asking for the salt, soccer games, dinner parties, lectures, and wedding ceremonies. Somebody else being engaged in a certain action or activity may (partly) make it appropriate or inappropriate for an individual to act in a certain manner: A wedding ritual taking place makes it appropriate to act in a non-disturbing manner. Likewise, entering the room where a friend's children are peacefully asleep makes it appropriate to lower one's voice.

I shall refer to these properties as the normatively relevant aspects of environments. Notice that it is typically possible directly to see that something is a bus, a beach, a table, or an altar; that somebody is a policeman on duty, a nurse on duty, or a pedestrian; that somebody is old, young, a man, or a woman; that somebody is asleep, or is sitting; that a wedding ceremony or a football game is taking place, and so on. In sum, many normatively relevant aspects of environments are directly perceptible: They fall in the category of everyday phenomena that qualify as directly perceptible according to the account of direct perception.

Turning to individuals, they have different kinds of properties that may, either singly or in combination, make it the case that an environment makes it appropriate or inappropriate for them to act in a given manner. Most notably, these properties are their social status, their physical/biological characteristics, and the action or activities in which they are engaged. Here are some examples of the role these may play:

- Social status: Being the host at a dinner party makes it inappropriate to be the first to serve oneself some food: The guests should begin. Being a passenger on an airplane makes it appropriate to return to one's seat when told to do so by the stewardess.

\footnotetext{
${ }^{3}$ It goes without saying that whether being on a beach makes it appropriate for women to wear nothing but a bikini depends on whether the beach is located in, say, a Western country. Here, and in the following, I ignore complications of this sort.

${ }^{4}$ Whether an individual is counted as old or as skinny is to an important extent a matter of convention. Referring to individuals' being old, skinny, and the like as their physical/biological characteristics should be seen as being perfectly compatible with this point.
} 
- Physical/biological characteristics: Being young and healthy makes it appropriate for an individual, in a crowded bus, to offer her seat to an elderly person. Being a woman makes it inappropriate to sit with one's legs spread.

- Action/activity: Sitting down makes it appropriate to offer one's bus seat to an elderly person standing up in the crowded bus. Being in the midst of finishing the preparation of the dinner makes it appropriate to leave it to one's partner to welcome the guests when they arrive.

I shall refer to these properties as the normatively relevant standings of individuals. Even if the normatively relevant standings of acting individuals are perceptible, it is only rarely that they take advantage of this opportunity. Typically, an individual does not look down herself to determine that she is a doctor or whether she is a man or a woman.

In light of these considerations, the proposal that the generation of true beliefs about normative states involves inferential activity may be specified as follows: The environment causes individuals, via the stimulation of their retinal cells, to form perceptual beliefs about one or several of its normatively relevant aspects. These beliefs combine with suitable background beliefs. Usually, the latter include individuals' beliefs about their normatively relevant standings and previously acquired beliefs about normatively relevant aspects of the environment. On this basis, individuals infer that the environment in front of their eyes makes some action appropriate or inappropriate. This line of thinking may be illustrated by way of the bus example: First, the individual forms the perceptual belief that an elderly person enters the bus. The individual combines her perceptual belief with background beliefs to the effect that she is sitting down, that she is young and generally fit to stand up, and that there are no free seats. Together these beliefs allow her to infer that she should offer the elderly person her bus seat. There is no doubt that true beliefs about normative states may be brought about in this fashion. Still, this is far from always the case. Sometimes true beliefs about normative states are not the upshot of either conscious, nonconscious, or weakly unconscious inferential activity. ${ }^{5}$ Or, so I shall now argue.

To begin with, environments may cause individuals, via the stimulation of their retinal cells, to form true beliefs about normative states without these beliefs being the result of conscious inferential activity, that is, inferential activity which is actively noticed. For instance, suppose that an individual is sitting in a crowded bus facing the bus door where an elderly person enters. This individual may react to the situation by instantaneously forming the belief that she should offer her bus seat to the elderly person. She simply finds herself with this belief. In this manner, true beliefs about normative states are sometimes phenomenologically immediate.

Also, but perhaps less evidently, environments may cause individuals, via the stimulation of their retinal cells, to acquire true beliefs about normative states without any nonconscious inferential activity taking place either. Recall that when individuals engage in nonconscious inferential activity, they do not notice this activity. Still, they might effortless have done so: It would only require them to pay attention to the matter. Against this background, consider the following scenario: Individuals who are used to Danish traffic signals are enrolled in an experiment. In the first part of the experiment, it is ensured that when they are placed in front of a cross walk, they do not engage in conscious inferential activity: They do not actively notice any conceptual representation of the little green man and a move from there to the belief that it is appropriate to walk. In the second part, they are once more placed in front of the cross walk where the

\footnotetext{
${ }^{5}$ The possibility that strongly unconscious activity occurs does not need to be rejected. As explained in Part I of this paper, there is no such thing as strongly unconscious inferential activity among conceptual representations.
} 
little man turns green. This time, they are given the task of attending to whether they engage in inferential activity in order to acquire the true belief that it is appropriate to traverse the cross walk. It is quite clear, I think, that most, if not all, of the participants in the experiment will answer that they detect no inferential activity. ${ }^{6}$ Generalizing from this example, it is reasonable to hold that an environment may cause individuals, via the stimulation of their retinal cells, to acquire true beliefs about normative states without these beliefs being the upshot of either conscious or nonconscious inferential activity.

The last option to be examined is whether environments may cause individuals, via the activation of their retinal cells, to acquire true beliefs about normative states without the occurrence of any weakly unconscious inferential activity. The latter is inferential activity which individuals do not actively notice unless they make a sustained effort in this direction. So, consider again the experiment with the individuals who are used to Danish traffic signals. Assume that it has already been determined that the participants do not engage in conscious or nonconscious inferential activity. On that basis, the participants are presented with a third task: They are required to make a sustained effort to notice whether their belief that it is appropriate to traverse the cross walk is the result of inferential activity. For instance, they may be placed several times in front of a cross walk where the little man turns green. Each time they are then invited to notice whether they engage in inferential activity. Or, they may be encouraged to train their ability to concentrate on the task of noticing inferential activity. Once they have done so, they are then expected to come back and go through the experiment again. Despite making such a sustained effort, I submit, most, if not all, of the participants in the experiment will answer that they do still not detect any inferential activity. And similar experiments, I think, will yield the same result. In this fashion, an environment may cause individuals, via the stimulation of their retinal cells, to acquire true beliefs about normative states without these beliefs being the upshot of either conscious, nonconscious, or weakly unconscious inferential activity. The finding means that beliefs about normative states may be brought about in a way that also fits the second part of the characterization of perception as process. ${ }^{7}$

There are no further requirements mentioned in the account of direct perception. Consequently, it may be concluded that, by the lights of the account, there are situations of social interaction in which individuals qualify as directly perceiving normative states. Everyday phenomena such as tomatoes and their being ripe, are not alone in meeting the necessary and sufficient conditions stated by the account of direct perception. Sometimes, these conditions are met by normative states as well. Moreover, it is fair to think that individuals may become reliably able to form perceptual beliefs about normative states. In situations of social interaction, they may possess - and exercise - the ability directly to perceive that the situation makes it appropriate for them to act in a given manner. For instance, they may

\footnotetext{
${ }^{6}$ The reader is invited to verify this claim by carrying out this, or a similar, experiment herself. In fact, I am using the cross walk example because it is a situation which the reader may easily seek out in order to confirm the claim that she will not, effortlessly, notice any inferential activity taking place. In this spirit, the reader is also invited to perform the next experiment to be discussed.

${ }^{7}$ In connection with the point that true beliefs about normative states may be inferentially acquired, it was noticed that background beliefs may figure as premises in these inferences. Background beliefs may also be assigned a role in the generation of noninferentially acquired true beliefs about normative states. More precisely, it may be maintained that individuals' background beliefs somehow penetrate the process which result in their perceptual beliefs about normative states. Or, it may be insisted that there are nonconceptual representational states and/or nonrepresentational states that fill in the same causal role as that assigned to background beliefs. For the present purpose, there is no need to take a stance on this complicated issue. It suffices to notice that it is typically the case that individuals' true noninferentially acquired beliefs about normative states may, at the very least, be construed as if penetrated by background beliefs.
} 
directly perceive that they should offer their seat to an elderly person, that they should say "thank you," that they should greet another person by saying "hi," that they should to stand in line, and that they should refrain from stripping naked.

\section{The Common Ability Directly to Perceive Normative States}

In order to ensure a fuller appreciation of the conclusion just reached, it is worth briefly to pause and consider to what extent the ability directly to perceive normative states is commonly acquired and exercised. To this end, I shall briefly discuss two ways in which individuals may acquire this ability.

One possibility is that an individual is first told how to infer the presence of a normative state from, among other things, the directly perceptible normatively relevant aspects of an environment. She begins to draw the suggested inference whenever she finds herself in that kind of situation. Then, after a period of training, the individual ceases to draw any conscious inference. Moreover, she does not draw any nonconscious or weakly unconscious inference either: Even if she were to pay attention to the matter, she would not, effortlessly or after making a sustained effort, notice any inferential activity taking place. At this point she sees, rather than infers, that the situation makes some action appropriate or inappropriate. She has become reliably able noninferentially to acquire the belief. An example may serve to illustrate this point. Assume that an individual is told that when she is sitting down in a crowded bus and an elderly person enters, she should offer her seat to that person. For a start, she draws the inference whenever she finds herself in that situation. Then, after a while, she becomes reliably able noninferentially to acquire the belief that she should offer an elderly person her seat. In other words, as the result of being repeatedly exposed to acting in that kind of situation, she acquires the ability directly to perceive that the situation makes it appropriate for her to act in this manner.

Another possibility is that individual is not directly told how to infer that some action is appropriate or inappropriate. Instead, all she has to go on is how competent individuals act and express approval and disapproval of others' actions. This is the most common situation. Here, the individual is likely to pick up on how it is appropriate or inappropriate to act insofar as she is repeatedly exposed to competent individuals' actions and their reactions to others' actions, including her own. More specifically, as she becomes used to acting in a given kind of situation, she is likely to begin, and eventually become reliably able, noninferentially to form true beliefs about the corresponding normative states. For instance, a little girl may see how her parents and other adults tend to offer their bus seat to elderly persons. Likewise, she may notice how they express their approval or disapproval of the manner in which she and others act in this situation: Her parents and other adults may make comments along the lines of "that was nice of the young man to offer his seat to the old woman" and "you should get up so that the old woman can sit down." Also, they may smile approvingly when she rises to her feet so that an elderly person can sit down. At some point, she is likely to catch on: She becomes able directly to perceive that a situation of that kind makes it appropriate for her to offer her bus seat to an elderly person.

Insofar as these accounts are recognized as plausible stories of how perceptual learning may take place, the following appears to be the case: It is first and foremost if individuals have been repeatedly exposed to acting in a given kind of situation of social interaction that they are likely to have - and exercise - the ability directly to perceive normative states. Since there are many kinds of social interaction that individuals take part in very often, even on a daily basis, the ability directly to perceive normative states should be seen as a commonly possessed - and exercised - ability. 


\section{The Ability to Act Appropriately}

There is only a small - and highly plausible - step from the claim that individuals sometimes have the ability directly to perceive normative states to the main contention that their exercise of this ability sometimes underwrites their ability to act appropriately. Consider the bus case one last time: An individual is on a crowded bus. An elderly person enters and the individual forms the perceptual belief that she should offer her seat to this person. It is reasonable to hold that it is this belief that, partially at least, causes her subsequent appropriate action: She gets up while saying to the old person "please, you can sit here." In a similar vein, it is fair to think that an individual's perceptual belief that she should, say, stand in line in the supermarket, say "thank you" upon receiving a gift, or greet another person by saying "hi" is what, partially at least, causes her subsequent appropriate actions. Generalizing from these cases, the thesis defended in the present paper may be regarded as vindicated: In situations of social interaction, individuals' ability to act appropriately sometimes depends on their exercise of the ability directly to perceive the appropriateness of actions.

\section{The Thesis as Supplement and Defense}

By way of ending, I should like briefly to discuss different ways in which the defense of my thesis is of importance to ability theorists of practice.

Most obviously, the supplement opens to ability theorists one approach to the study of particular practices that involve social interaction: Ability theorists should examine individuals' ability to act appropriately from the perspective of its being sometimes a function of their exercise of the ability directly to perceive normative states. Sometimes, ability theorists will then be able to explain individuals' appropriate ways of acting by appeal to their direct perception of corresponding normative states. An account along these lines brings into view how individuals being reliably able to act appropriately is a matter of their constantly attuning to, or being responsive to, the environment in which they find themselves. By implication, attention is directed to the fact that the ability to act appropriately cannot be understood and explained apart from the environment in which it is exercised. These are important insights that ability theorists may bring to the field, and apply, when studying specific practices of social interaction.

Ability theorists may also make use of the supplement in another way. It includes an account of the ability directly to perceive something to be the case. Evidently, individuals do not merely exercise this ability in relation to normative states. They directly perceive a lot of other things to be the case too. Moreover, individuals exercise their ability directly to perceive something to be the case in many other situations than those involving social interaction. This being the case, ability theorists may avail themselves of the account of direct perception in many other contexts of study. For instance, an ability theorist may want to study practices specified as scientific practices. The account of perception may here put the ability theorist in a better position to understand and explain scientists' perceptual abilities and the role these play when they carry out their scientific activities.

These considerations point to two reasons why the supplement is useful to ability theorists in their study of practices. Additionally, the supplement may serve as a response to an important type of objection launched against theories of practice in general. In his very influential and highly critical book, The Social Theory of Practices, Stephen Turner states that the notion of practice "is deeply elusive" (Turner 1994:2). Moreover, he contends that any attempt to turn the notion into a clear and useful concept is doomed to fail: "The idea of 'practice' and its cognates has this odd kind of promissory utility. They promise that they can be turned into something more precise. But the value of the concepts is destroyed when they 
are pushed in the direction of meeting their promise" (ibid.:116). ${ }^{8}$ Though Turner exaggerates, I think he is right that theories of practice may benefit from further clarification and elaboration. Yet, as opposed to Turner, I believe that the task may be carried out successfully. And what is more, I take the supplement I have offered to prove this point. The supplement provides a detailed specification of a special kind of practices, namely practices of social interaction: It offers an analysis of individuals' ability to act appropriately as this ability relates to, and is a function of, the ability directly to perceive normative states. The analysis clearly enhances, rather than destroys, the value of ability approaches. In this fashion, the supplement is a powerful answer to the kind of criticism advanced by Turner. It demonstrates that, in this respect at least, the basic ability approach is a viable approach: It is far from being an unpromising research program within social theorizing.

\section{Acknowledgement}

I would like to thank Robert Brandom and Peter Machamer for helpful comments and inspiring discussions. Also, I am grateful for the suggestions made by the anonymous referees and the editor of this journal.

\footnotetext{
${ }^{8}$ It may be noticed that Turner also raises a number of more specific objections to theories of practice. Space does not permit a discussion of these other objections. In my view, they do not apply to ability theories of practice as I have presented this approach.
} 


\section{Bibliography}

Turner, S. (1994). The Social Theory of Practices. Chicago: The University of Chicago Press.

Julie Zahle is assistant professor, Section of Philosophy, Department of Media, Cognition and Communication, University of Copenhagen. Her main area of research is the philosophy of the social sciences and, in particular, the philosophy of anthropology and sociology. She has written on the individualism/holism debate and on the method of participant observation. 